\title{
Polycystic ovarian syndrome and pregnancy outcome
}

\author{
Chaitra Shivananjaiah*, Abinaya Kannan, Mridula Devi, Jayanthi, \\ Satish D., Renuka Ramaiah
}

Department of Obstetrics and Gynecology, ESIC Medical College and Hospital, Bangalore, Karnataka, India

Received: 15 July 2017

Accepted: 24 July 2017

\author{
*Correspondence: \\ Dr. Chaitra Shivananjaiah, \\ E-mail: chaittra.shiv@gmail.com
}

Copyright: (c) the author(s), publisher and licensee Medip Academy. This is an open-access article distributed under the terms of the Creative Commons Attribution Non-Commercial License, which permits unrestricted non-commercial use, distribution, and reproduction in any medium, provided the original work is properly cited.

\begin{abstract}
Background: Polycystic ovarian syndrome (PCOS) in the present generation is a very common reproductive disorder and the prevalence is on the rise. It is associated with typical features such as insulin resistance, hyperandrogenemia and obesity which has deep implications on the pregnancy outcomes as well as a long-term health of the woman.

Methods: Prospective comparative study performed over 200 pregnant women in the ESIC medical college, Bangalore. 100 women diagnosed with PCOS were compared with that of 100 normal women. The method of conception in pcos was recorded. maternal outcome in the form of abortion, gestational diabetes mellitus, hypertensive disorder in pregnancy, mode of delivery, intrapartum and postpartum complication. Fetal outcome in the form preterm delivery, small-for-gestational-age (SGA) infants, large-for-gestational-age infants, apgar at 5 minute and admission to NICU.

Results: Of the 100 women who were diagnosed with PCOS, 62 had spontaneous conception, 32 conceived with ovulation induction, 4 with artificial insemination and 2 needed IVF for conception. 18 women had spontaneous abortion, 58 were diagnosed with Gestational diabetes mellitus (GDM) predominantly between 24 - 28 weeks' period of gestation, 16 women had hypertension complicating pregnancy. Fetal outcome in the form of preterm birth was noted in 14 patients, large for gestation was noted in 11 newborns, the rate of NICU admission was significantly higher in the PCOS women's infants constituting 33\%.

Conclusions: The assistance needed for conception was significantly higher in women with PCOS. The complications associated with pregnancy such as spontaneous abortions, gestational diabetes, hypertensive disorder in pregnancy, preterm births, need of NICU care for the infants are much higher in women with PCOS. Adult health education and the preconception diagnosis and appropriate management of PCOS is an important primary mode of prevention of these associated complications.
\end{abstract}

Keywords: Gestational diabetes mellitus, Hyperandrogenemia, Insulin resistance, Obesity, Polycystic ovarian disease, Preterm

\section{INTRODUCTION}

In a developing country like ours, which is the diabetic capital of the world, Polycystic ovary syndrome (PCOS) is one of the top listed endocrine disorders in women between 13 to 40 years of reproductive age. ${ }^{1}$ Prevalence of the disease is between 5 to $10 \%$. $^{2}$ Stein and Levinthal was the first to describe the condition. ${ }^{3}$ Rotterdam ESHRE/ASRM in the year 2003 standardized the definition of PCOS, which is characterized by a combination of oligomenorrhea / amenorrhea, clinical or endocrine signs of hyperandrogenemia and polycystic ovaries. $^{4} 70 \%$ of the women suffer from normogonadotrophic anovulation, but with the presence of the ultrasound or endocrine features of PCOS..$^{5}$ More than $50 \%$ of women diagnosed with PCOS are overweight or obese. ${ }^{6}$ This metabolic disorder is most commonly associated with infertility. $15-20 \%$ of the 
women have miscarriages and up to $30-35 \%$ of them have early pregnancy losses. The late complication in pregnancy like gestational diabetes mellitus explained by $25-70 \%$ of the women with PCOS having insulin resistance, hypertension complicating pregnancy and prematurity. $^{7}$ PCOS is also associated with high incidence of cardiovascular disease later in life and developed type II diabetes or impaired glucose tolerance in the early 40 's. ${ }^{7,8}$

The 'Barker hypothesis' explains that the fetal nutrition and endocrine environment affects the developing neuroendocrine systems leading to long term health hazards. ${ }^{9}$ The low fertility in these women make it a must for them to have reproduction assistance like ovulation induction or IVF, putting them at the risk of developing multiple gestation. ${ }^{10,11}$

The objective of present study is to compare the mode of conception, need of reproductive assistance, maternal and fetal outcome in the form of spontaneous abortions, gestational diabetes, hypertensive disorders of pregnancy, preterm, birth weight and need of NICU care.

\section{METHODS}

Prospective comparative study performed over 200 pregnant women in the ESIC medical college, Bangalore. 100 women attending the antenatal clinic without previous history or medical records of PCOS and no medical disorder were grouped as the control group and women with medical records in the form of ultrasound or blood parameters conclusive of PCOS were categories as the study group. Detailed history was taken of all the 200 women which including the age, parity, obstetric history, spontaneous or assisted conception, history of metformin intake, examination findings including BMI, facial hair, acne. Patients were labeled as GDM after performing 100 gms of glucose tolerance test (GTT) by the hexokinase method, and if 2 or more value was found to be abnormal.

Hypertensive disorders in pregnancy was diagnosed when the blood pressure was greater than $140 / 90 \mathrm{~mm} \mathrm{Hg}$ after 20 weeks' period of gestation, on 2 or more occasions, and women with proteinuria were labeled as preeclampsia. Delivery prior to 37 weeks of gestation were labeled as preterm. When the birth weight was less than 2500 gms were termed low birth weight and birth weight of more than 4000 gms were macrosomia.

\section{RESULTS}

The basic characteristic of both the population are depicted in Table 1.

Parameters such as age, obstetrics index, BMI, family and past history of blood sugar abnormality, history of abortion, mode of conception was compared and found to be significantly different in both the groups.
Table 1: characteristics of the study population.

\begin{tabular}{|l|l|}
\hline Parameters & Number (100) \\
\hline Age (years) & \\
\hline $20-24$ & 26 \\
\hline $25-29$ & 48 \\
\hline $30-34$ & 16 \\
\hline$\geq 35$ & 10 \\
\hline Parity & \\
\hline Primi & 39 \\
\hline multi & 61 \\
\hline BMI & \\
\hline Normal weight & 56 \\
\hline Over weight & 39 \\
\hline Obese & 5 \\
\hline Mode of conception & \\
\hline spontaneous & 62 \\
\hline Ovulation induction & 32 \\
\hline IVF & 2 \\
\hline Artificial insemination & 4 \\
\hline
\end{tabular}

The highest prevalence of PCOS, were in the between the age group 25 to 29 years, constituting to $48 \%$. $39 \%$ were primigravida, $62 \%$ of the women conceived spontaneously.

Up to $38 \%$ of the women needed assistance in reproduction, $32 \%$ of the women conceived following ovulation induction, predominantly in the second cycle.

Table 2: Maternal outcome.

\begin{tabular}{|llll|}
\hline Parameters & $\begin{array}{l}\text { Normal } \\
\text { women }\end{array}$ & $\begin{array}{l}\text { PCOS } \\
\text { women }\end{array}$ & $\begin{array}{l}\text { P } \\
\text { value }\end{array}$ \\
\hline Spontaneous miscarriage & 6 & 18 & $>0.05$ \\
\hline GDM & 12 & 58 & $<0.05$ \\
\hline $\begin{array}{l}\text { Hypertensive disorders } \\
\text { of pregnancy }\end{array}$ & 7 & 16 & $>0.05$ \\
\hline Preterm & 6 & 14 & $<0.05$ \\
\hline
\end{tabular}

The Table 2 indicates the maternal outcome: $25 \%$ of the women had spontaneous miscarriage. The $\mathrm{p}$ value was found to be significant in relation to the prevalence of gestational diabetes which was as high as $58 \%$ in the PCOS women. $64 \%$ had a normal vaginal delivery and $36 \%$ had LSCS.

Table 3: Fetal outcome.

\begin{tabular}{|llll|} 
Parameters & $\begin{array}{l}\text { Normal } \\
\text { women }\end{array}$ & $\begin{array}{l}\text { PCOS } \\
\text { women }\end{array}$ & $\begin{array}{l}\text { P } \\
\text { value }\end{array}$ \\
\hline Low birth weight & 6 & 13 & $>0.05$ \\
\hline Macrosomia & 3 & 11 & $>0.05$ \\
\hline NICU admission & 7 & 33 & $<0.05$ \\
\hline
\end{tabular}

Table 3 shows fetal outcome, the $\mathrm{p}$ value was significant in the need of NICU care for the infants, predominantly due to preterm and low blood sugars. 


\section{DISCUSSION}

Present study conducted on a total of 200 pregnant women, 100 of who were among the women who had a history of PCOS (i.e. either in the form of scan or positive blood parameters). Age and parity distribution in both the groups were comparable. Out of 100 normal women, $21 \%$ landed with complications were as unto $60 \%$ of women with PCOS landed with antenatal complications.

Infertility was common among the PCOS patients, in our study. We noted that $38 \%$ women needed help in conceiving. Insulin resistance, hyperinsulinaemia and obesity are the common clinical features with women in PCOS. Women with PCOS were found to have an increased risk of carbohydrate metabolism impairment. The age of the patients in our case control study had no significant difference unlike in consensus with a study conducted by Haakoova et al and Setji et al whereas the weight difference were significantly different among both the groups. ${ }^{12,13}$

The maternal complications in the form of spontaneous abortion in our study was higher than the normal population, but the $p$ value was not significant with was the same results obtained in a study conducted by Nivedhitha et al. ${ }^{14}$ There was a considerable difference in the prevalence of the hypertensive disorder in pregnancy, but in comparisons to the normal population it was not statistically significant, wihch was the same results obtained by Setji et al. ${ }^{13}$ Prevalence of Gestational diabetes is not only high among the women with PCOS but also statistically significant, upto $58 \%$ of the women were GDM of whom $84 \%$ were diagnosed between $24-28$ weeks period of gestation, which was the same results found in a large number of study conducted by Haakoova et al, Setji et al and Lo JC et al. ${ }^{12,13,16}$ Holter et al who conducted a large retrospective study found only a marginal increase in the risk of GDM, but no important difference in the rate of preeclampsia, but found that it had a direct relation to the body mass index of the patients. ${ }^{15}$

Boomsma performed GTT in the antenatal clinic in normal and PCOS patients and correlated with the weight of the women but found no significant difference, whereas we found a significant difference in the blood sugars and also women with PCOS developed GDM in the later second and early third trimester unlike the normal women who were all diagnosed in the third trimester. ${ }^{17}$ The preterm prevalence was higher in the PCOS women but not significant which was the same results obtained by Nivedhitha et al and Boomsma et al. ${ }^{14,17}$

The rate of Caesarean Section Rate, we found no significant difference between PCOD women and normal women, in contrast to a study conducted by Bjercke $\mathrm{S}$ et.al. who found a statistical significance in the need of caesarean section. ${ }^{18}$

The fetal outcome in terms of NICU admission was significantly higher in the babies born to the PCOS women with a $\mathrm{p}$ value of $<0.05$. The most common reason for the need of NICU care was preterm and neonatal hypoglycemia.

\section{CONCLUSION}

The complication associated with PCOS is not just confined to reduced fertility but also pregnancy complications like spontaneous abortions, gestational diabetes, hypertensive disorders of pregnancy, fetal complication like low birth weight, increase need of NICU care, lower Apgar. Hence routine screening for blood sugar abnormalities, obesity, oligo menorrhea is to be managed enthusiastically in adulthood. Meta-analysis has found that the Incorporation of metformin benefited in many PCOS women with infertility. Routine antenatal screening and early diagnosis of GDM and hypertensive disorders can provide a better fetal and maternal outcome.

\section{Funding: No funding sources Conflict of interest: None declared \\ Ethical approval: The study was approved by the Institutional Ethics Committee}

\section{REFERENCES}

1. Franks S. Polycystic ovary syndrome. N Engl J Med. 2001;333:853-61.

2. Archer JS, Chang RJ. Hirsutism and acne in polycystic ovary syndrome. Best Pract Res Clin Obstet Gynaecol. 2004;18:737-54.

3. Stein IF, Leventhal ML. Amenorrhea associated with bilateral polycystic ovaries. Am J Obstet Gynecol. 1935;29:181-91.

4. The Rotterdam ESHRE/ASRM-sponsored PCOS consensus workshop group. Revised 2003 consensus on diagnostic criteria and long-term health risks related to polycystic ovary syndrome. Human Reprod. 2004;19:41-7.

5. Laven JS, Imani B, Eijkemans MJ and Fauser BC. New approach to polycystic ovary syndrome and other forms of anovulatory infertility. Obstet Gynecol Surv. 2002;57:755-67.

6. Norman RJ, Noakes M, Wu R, Davies MJ, Moran L, Wang JX. Improving reproductive performance in overweight/obese women with effective weight management. Hum Reprod Update. 2004;10:267-80.

7. Legro RS, Castracane VD, Kauffman RP. Detecting insulin resistance in polycystic ovary syndrome: purposes and pitfalls. Obstet Gynecol Surv. 2004;59:141-54.

8. Wild RA. Long-term health consequences of PCOS. Hum Reprod Update. 2002;8:231-41. 
9. Barker DJ. Fetal programming of coronary heart disease. Trends Endocrinol Metab. 2002;13:364-8.

10. Balen AH, Braat DD, West C, Patel A, Jacobs HS. Cumulative conception and live birth rates after the treatment of anovulatory infertility: safety and efficacy of ovulation induction in 200 patients. Hum Reprod. 1994;9:1563-70.

11. Eijkemans MJ, Imani B, Mulders AG, Habbema JD, Fauser BC. High singleton live birth rate following classical ovulation induction in normogonadotrophic anovulatory infertility (WHO 2). Hum Reprod. 2003;18:2357-62.

12. Haakoova L, Cibula D, Rezabek K, Hill L,Fanta M. Pregnancy Outcome in women with PCOS and controls matched by age and weight. Human Reprod. 2003;18(7):1438-41

13. Setji TL, Brown AJ, Feinglos MN. Gestational diabetes mellitus. Clin Diab. 2005;23(1):17-24.

14. Nivedhitha VS, Sankareswari R. Pregnancy outcome in women with polycystic ovary syndrome. Int $\mathbf{J}$ Reprod Contracept Obstet Gynecol. 2015;4:1169-75.
15. Holte J. Disturbances in insulin secretion and sensitivity in women with the polycystic ovary syndrome. Ballieres Clin Endocrinol Metab. 1996;10:221-47.

16. Lo JC, Feigenbaum SL, Escobar GJ, Yang J, Crites YM, Ferrara A. Increased prevalence of gestational diabetes mellitus among women with diagnosed polycystic ovary syndrome: a population based study. Diab Care. 2006;29(8):1915-21.

17. Boomsma CM, Eijkemans MJC, Gughes EG, Visser GHA, Fauser BCJM, Maclon NS. A meta analysis of pregnancy outcomes in women with polycystic ovarian Syndrome. Hum Reprod. 2006;12(6):673-83.

18. Bjercke S, Dale PO, Tanbo T, Storeng R, Ertzeid G, Abyholm T. Impact of insulin resistance on pregnancy complications and outcome in women with polycystic ovary syndrome. Gynecol Obstet Invest. 2002;54:94-8.

Cite this article as: Shivananjaiah C, Kannan A, Devi M, Jayanthi, Satish D, Ramaiah R. Polycystic ovarian syndrome and pregnancy outcome. Int $\mathrm{J}$ Reprod Contracept Obstet Gynecol 2017;6:3804-7. 